This item was submitted to Loughborough's Research Repository by the author.

Items in Figshare are protected by copyright, with all rights reserved, unless otherwise indicated.

\title{
A web-based information system to support end-of-life product recovery
}

PLEASE CITE THE PUBLISHED VERSION

PUBLISHER

Professional Engineering Publishing / @ IMechE

VERSION

VoR (Version of Record)

LICENCE

CC BY-NC-ND 4.0

REPOSITORY RECORD

Rahimifard, Aysin, Stephen T. Newman, and Shahin Rahimifard. 2019. "A Web-based Information System to Support End-of-life Product Recovery”. figshare. https://hdl.handle.net/2134/5057. 
This item was submitted to Loughborough's Institutional Repository (https://dspace.lboro.ac.uk/) by the author and is made available under the following Creative Commons Licence conditions.

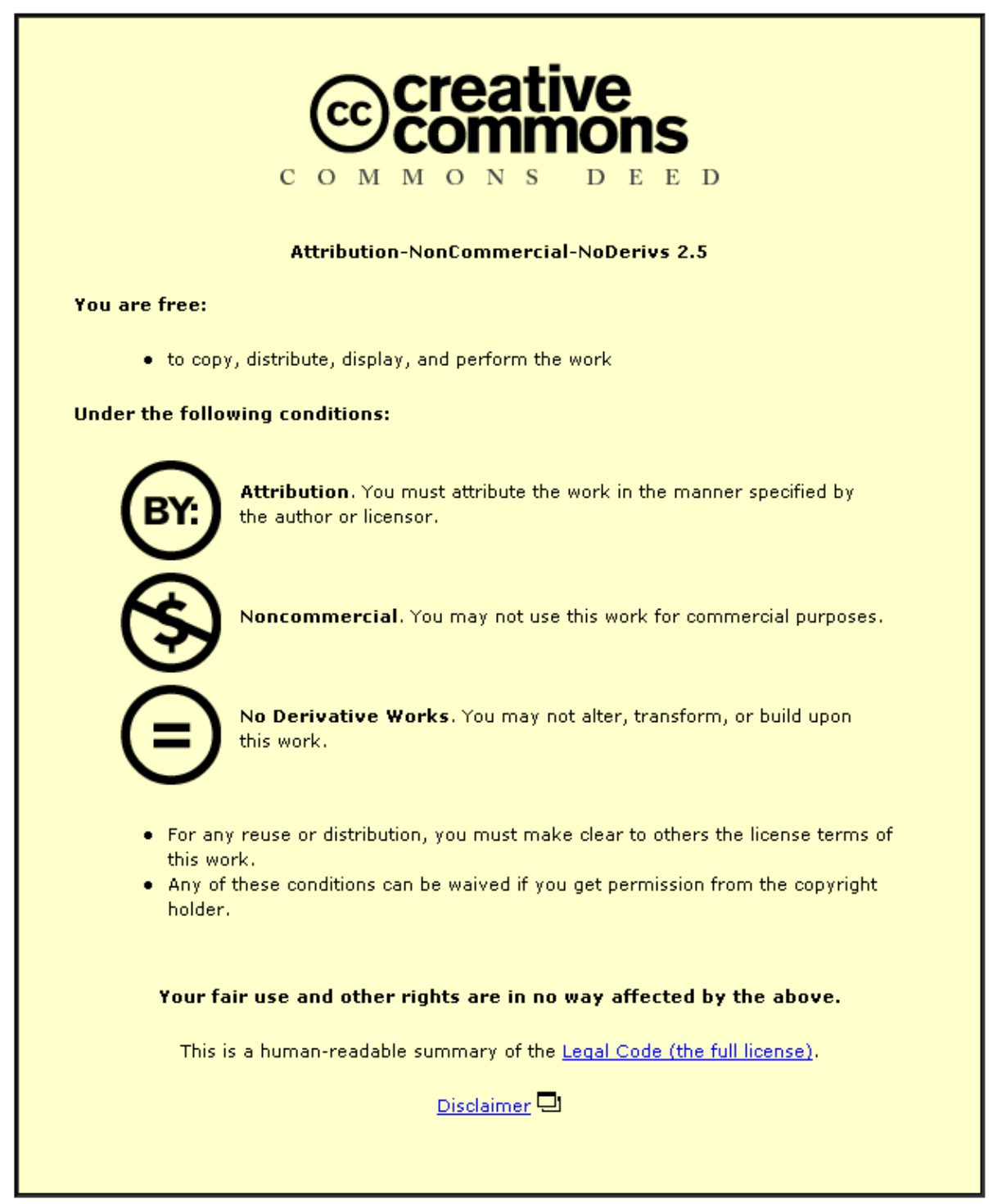

For the full text of this licence, please go to: http://creativecommons.org/licenses/by-nc-nd/2.5/ 


\title{
A web-based information system to support end-of-life product recovery
}

\author{
A Rahimifard*, S T Newman and S Rahimifard \\ Advanced Manufacturing Systems and Technology Centre, Wolfson School of Mechanical and Manufacturing \\ Engineering, Loughborough University, Loughborough, Leicestershire, UK
}

\begin{abstract}
Increased public awareness towards global environmental problems has forced manufacturing companies to consider the negative impacts of their activities on the environment. In this context, the effective management of products at the end of their useful life has become of paramount importance due to the ever-increasing national and international legislation and directives aimed at making take-back and recovery of used products obligatory for the original equipment manufacturer. This highlights a need for a systematic approach for enhancement of information, business and production management systems to deal with additional activities and processes related to the recovery of products. The research reported in this paper has developed a five-stage methodology to support product end-of-life management within manufacturing companies. The modelling and design of appropriate product recovery information systems, which constitute the main core of this methodology, are also described. The paper concludes with the description of an application of this methodology and information system design for the recovery of cutting tools at the end of their useful life in metalworking applications.
\end{abstract}

Keywords: product take-back, end-of-life management, environmentally conscious manufacturing, recycling of cutting tools

\section{INTRODUCTION}

Mass industrialization over the last century has had a negative impact on the natural environment, contributing towards serious problems such as global warming, ozone depletion, acid rain and, more importantly, serious depletion of natural resources. As a result, there is an increasing demand by customers, governments and the public for manufacturing industry to minimize any negative impact of their products and operations on the natural environment. This has resulted in significant research in the popular subject of environmentally conscious manufacturing (ECM), which is concerned with developing methods, procedures and equipment for manufacturing applications to satisfy the increasing number of environmental standards and legislation.

One of the major research areas within ECM is product recovery (PR) which is the transformation of used and discarded products into useful condition through remanufacture, reuse and recycling. In this context, two major

\footnotetext{
The MS was received on 17 September 2003 and was accepted after revision for publication on 7 May 2004.

*Corresponding author: Advanced Manufacturing Systems and Technology Centre, Wolfson School of Mechanical and Manufacturing Engineering, Loughborough University, Loughborough, Leicestershire LE11 3TU, UK.
}

directives of European legislation, namely the end-of-life (EoL) vehicle and the waste from electric and electronic equipment directives, will make take-back and recovery of used products obligatory for the original equipment manufacturer (OEM). This has generated concerns and significant interest in PR procedures not only among the OEMs, but also among the extended enterprises within the supply chain of these sectors, which include a large number of small and medium enterprises (SMEs).

Currently there is a large number of recycling and recovery applications within many different industrial sectors, which are often developed on an ad hoc basis and mainly due to the hidden economic value within used products. The authors argue that, in order to make a desired environmental impact, the number of PR applications has to be significantly increased and ideally be implemented in every manufacturing application. One of the main obstacles reported in the literature in achieving such large-scale PR implementation is the lack of formal methods and appropriate supporting information systems [1].

The research reported in this paper has generated a novel systematic five-stage methodology to support the product EoL management in manufacturing applications, entitled 'product recovery implementation methodology' 
(PRIME). At the core of PRIME is the specification and design of appropriate information systems to underpin the various stages of this methodology. The initial part of the paper provides a review of relevant literature, together with a brief description of the various stages involved in the PRIME methodology. The latter sections describe the modelling and design of a Web-based PR information system and discuss the application of the PRIME methodology to the recovery of cutting tools within machining applications.

\section{REVIEW OF RELEVANT RESEARCH}

The increasing significance of PR within manufacturing activities has brought a corresponding influence in research covering the various stages of the production life cycle [2]. New design concepts have emerged such as design for disassembly, remanufacturing, reuse and recycling which incorporate EoL decision considerations as design objectives [3-5]. Determining the EoL option for discarded products is closely related to disassembly planning, and therefore there are a number of studies that have explored the most appropriate level of disassembly and disassembly planning and sequencing [6-9].

In addition, a number of researchers have investigated a range of factors such as the economical, technical, environmental and social criteria, which influence the EoL options [10-14]. There are also a number of studies exploring the use of existing and novel production planning and control approaches for coordination of product recovery operations on the shop floor [15-18]. Inventory control within recovery systems has been recognized as different from traditional manufacturing systems due to a high degree of uncertainty in timing, quantity and quality of the returned products $[\mathbf{1 9}, \mathbf{2 0}]$.

A significant body of research has explored the new material flow within PR applications from the user to the producer, which is often referred to as reverse distribution and includes the collection and transportation processes [21, 22]. The establishment of $P R$ procedures within various manufacturing applications have also resulted in the emergence of new activities and actors required to accomplish recovery processes at the end of a product's life. These activities include collection of used products, assessing and routing, reprocessing them for product, part or material reclamation, redistribution of the recovered products and material, and finally safe disposal of waste. These activities have been investigated under the broader perspectives such as the product supply chain and the extended enterprise [23, 24], and also being linked with the various functions of production planning and control [25]. The requirements for PR information models and systems have also been considered with a number of bespoke solutions being identified [26-28].

The existing research in this area has provided an initial basis to support a sustainable approach to EoL and PR activities. However, because of the extreme requirements for rapid growth of these activities across the globe, there is a need for a more holistic systematic approach to support all aspects of EoL and PR. The focus of the research in this paper is on the first steps towards such a holistic vision through a 'product recovery implementation methodology' (PRIME).

\section{PRODUCT RECOVERY IMPLEMENTATION METHODOLOGY}

EoL PR relies on a technological solution together with a comprehensive understanding of the business, environmental, engineering and cost issues. The adoption of PR procedures within manufacturing enterprises requires a major alteration to both the internal and the external business and operational structures. This necessitates a number of changes in business and manufacturing practices, organizational structure, supporting information infrastructure and the operating market. Clearly, there should be an in-depth understanding of implications of these changes on the existing manufacturing activities to ensure the generation of a cost effective and efficient PR procedure. As a result, a novel systematic five-stage methodology, PRIME, has been developed. This methodology aims to provide a stepwise approach for identification of business, technological, process, resources and information requirements for the adoption of PR in different applications. The goal is to provide general tactical insights into decisions to be made during adoption of PR procedures rather than to optimize the decisions derived. The various stages of PRIME have been described in detail by Rahimifard et al. [29] and are outlined below:

(a) evaluation of business implications;

(b) assessment of available recovery technologies;

(c) identification of resource requirements;

(d) evaluation of logistics and operation planning requirements;

(e) development of a PR information system.

At the core of the methodology is the realization of appropriate information systems to support the information flow between various stages of PR implementation, as depicted in Fig. 1. The remaining sections of this paper describe the modelling, design and implementation of such PR information systems.

\section{MODELLING AND DESIGN OF INFORMATION SYSTEMS TO SUPPORT PRODUCT RECOVERY}

\subsection{Information modelling for product recovery}

The adoption of PR within any manufacturing application results in the generation of a large amount of information 
related to collection, assessment, remanufacturing processes, including information on material characteristics, disassembly maps, sales and distribution, warranties and maintenance, product utilization and EoL condition of the used product. Clearly, such information must be efficiently stored, maintained and accessed by a number of different actors involved in various PR activities.

In recent years, significant research effort has been directed at modelling, design and development of appropriate information systems to support a wide range of functions within various manufacturing applications [30]. Information models contain unambiguous definitions of data, its structure and relationships and are often generated to support the design of information systems and/or integration of a number of software systems. A large number of approaches, methods and tools have been developed for information modelling, which include both graphical and textual representations. Currently within modern manufacturing enterprises, these methods and approaches have been utilized to design and implement information systems based on a number of information models, including those for products, processes, resources and in some applications for customer orders.
In this research the Booch methodology [31] has been utilized to specify and demonstrate the range of EoL-related information required to support PR. The Booch methodology utilizes an object-oriented approach for system design and information specification, which is achieved through the application of class and inheritance diagrams. The typical information related to EoL management of the used products is illustrated in Fig. 2 and can be broadly categorized as follows:

1. $P R$ information. This contains product information such as material used, product design, bill of disassembly, possible recovery options, material recycling properties, legislative properties about use, and recovery and disposal of the product.

2. Remanufacturing information. This consists of information relating to the types of recovery process and their properties and the resources that can perform these processes which could include both external resources such as subcontracting companies as well as internal resources such as additional work centres and skilled labour specialized in disassembly, repair and reassembly.

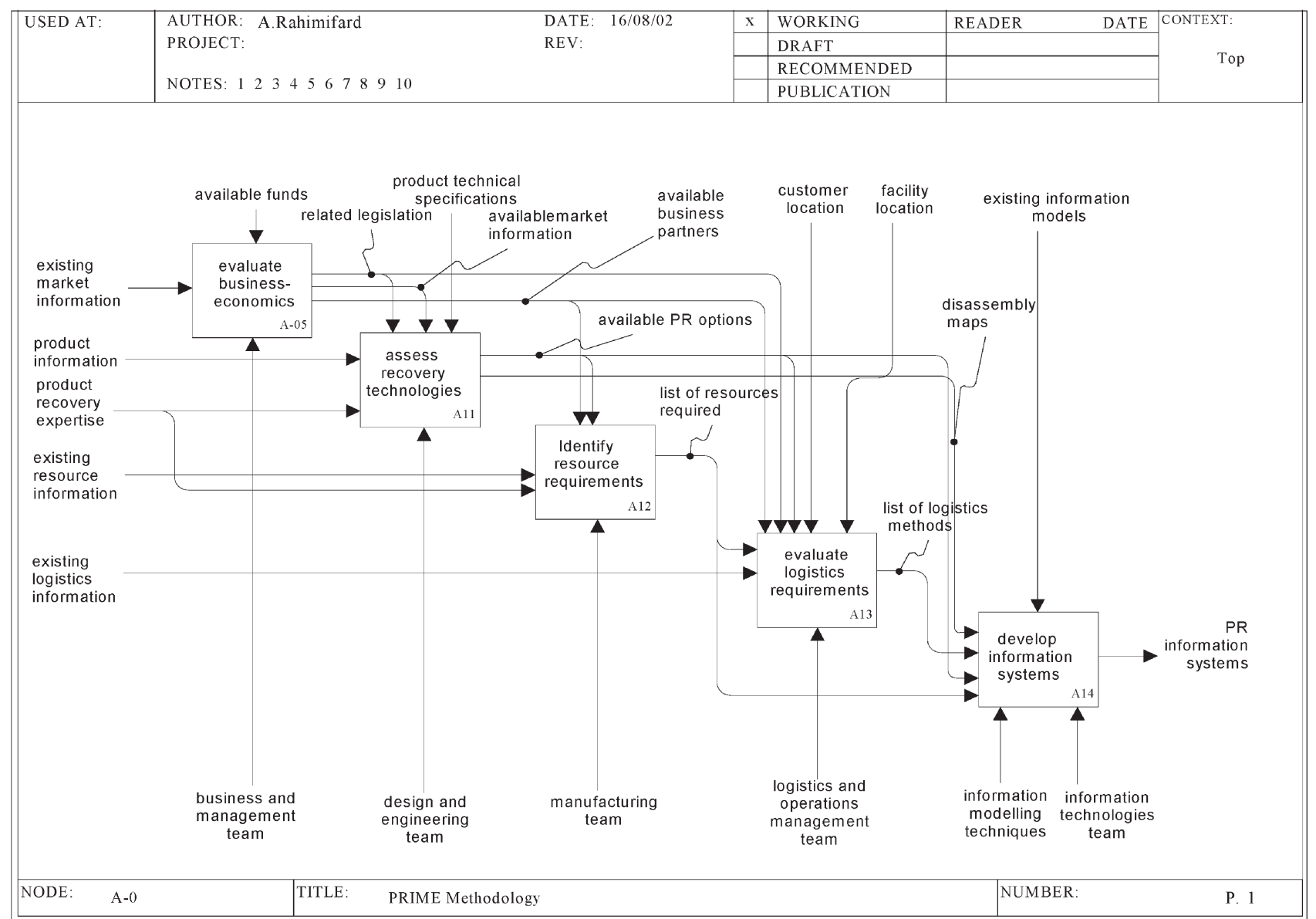

Fig. 1 IDEF0 representation of the activities involved in PRIME methodology 


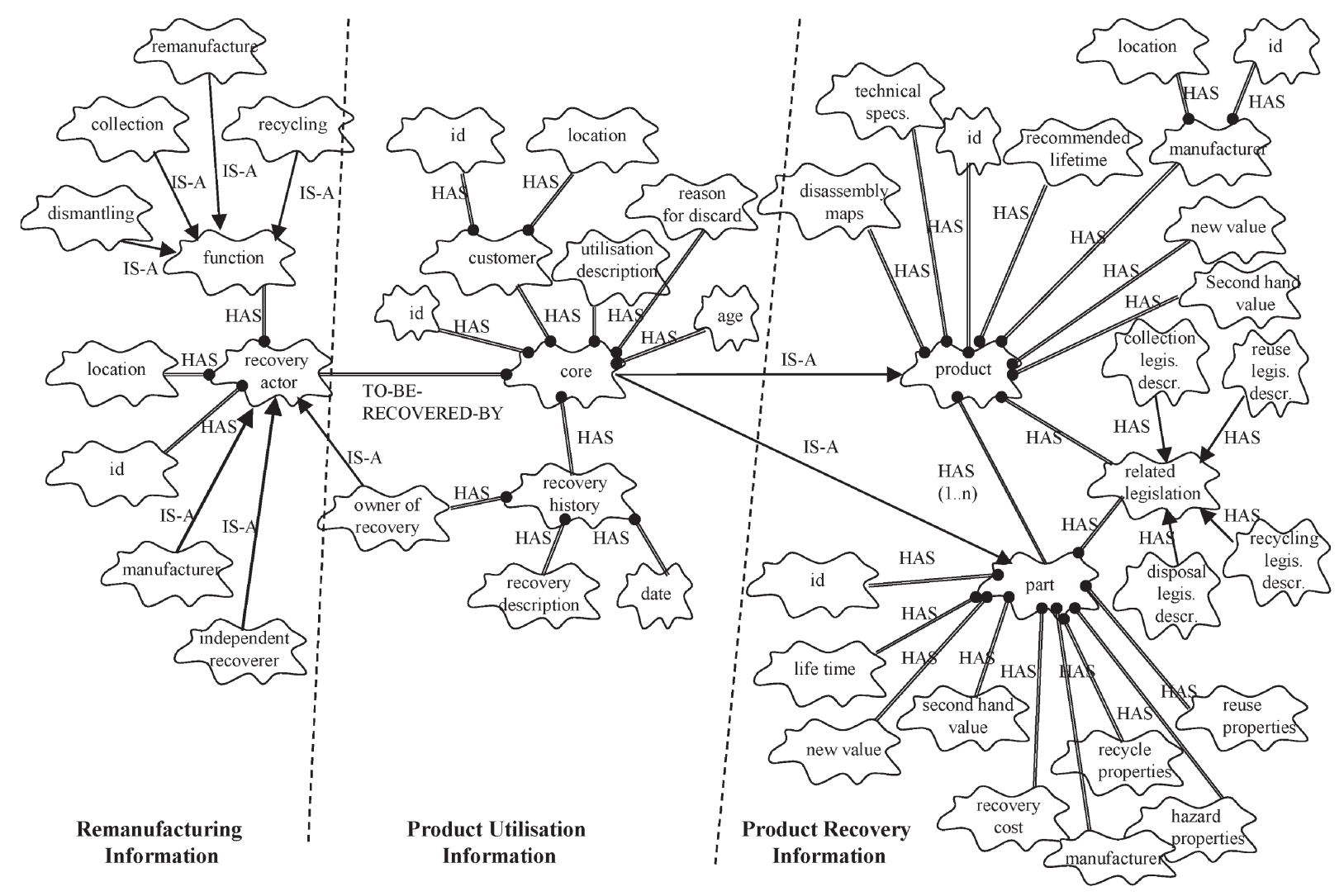

Fig. 2 Representation of PR information using Booch methodology

3. Product utilization information. This provides a history of product use and the condition of the product at the EoL (commonly referred to as the core), which includes information about the customer, purpose of use, age, reasons for discard and failure history. Furthermore, in applications where a product can be recovered a number of times, the history of the previous recovery operations is also maintained.

\subsection{Information system design for product recovery}

Typically, there are two stages involved in design of an information system, namely the design of a data repository and an information network. In the case of a PR information system, there are two possible options for the design of a data repository system, as illustrated in Fig. 3. In the first option, the PR-related information (i.e. product recovery, remanufacturing and product utilization information) can be viewed as extension to the information maintained within the existing product and manufacturing models. Such an approach is particularly suitable for an OEM which is responsible for both the manufacture and the recovery of products. Alternatively, in applications where there is not an established or common product and manufacturing models, a more effective approach would be to generate a bespoke
PR information model. For example, in the cases where an independent recoverer is responsible for the recovery of a range of products, often manufactured by a wide range of producers, a bespoke data repository system may be the only cost effective and feasible method of storing and maintaining PR-related information.

The second stage of information systems design involves the definition of an information network to facilitate the access to the data repository. Owing to the inherited distributed nature of PR procedures, related actors and users of such information systems may be physically located across cities, countries and even continents. The recent advancements in Webbased information management systems provide a suitable technological solution to the design of a distributed PR information network. A Web-based information system allows multiple, simultaneous and distributed access and also provides an appropriate infrastructure to support the collaborative approach to product recovery by various actors involved in PR procedures. Furthermore, the platform-independent architecture associated with Web-based information systems [32] eliminates barriers to integration and allows recovery actors to deploy applications across the entire product supply and recovery chain, which can include material suppliers, manufacturers, customers, collectors and reprocessors whose computing environments may be 


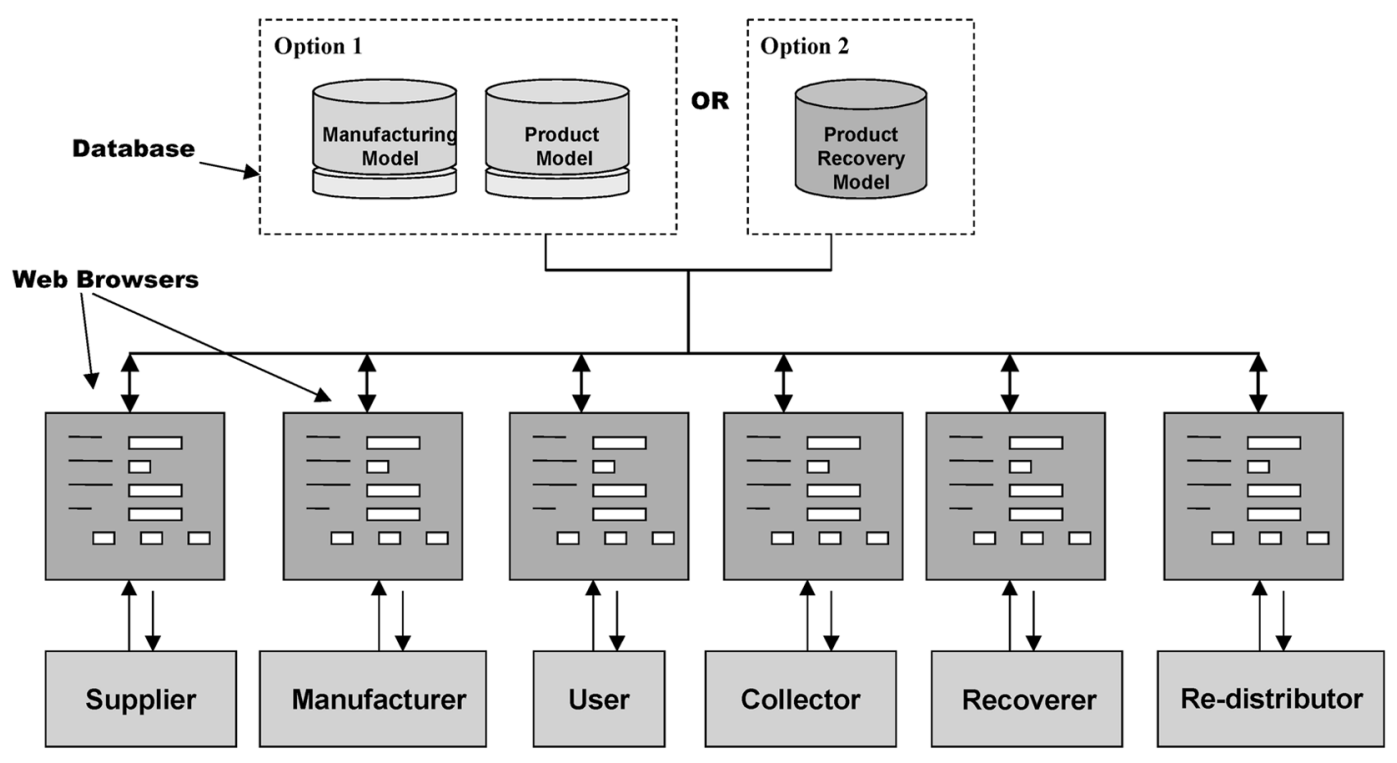

Fig. 3 Pictorial presentation of a Web-based PR information system

completely different. As a result, such a Web-based approach to information network design is proposed by the present authors to be the future information management tool for supporting PR activities, as illustrated in Fig. 3. The implementation of one such Web-based information network for the recovery of cutting tools is described in the next section of this paper.

\section{APPLICATION STUDY: INFORMATION SUPPORT FOR RECOVERY OF CUTTING TOOLS}

\subsection{Recovery of cutting tools}

The recovery of cutting tools within metalworking applications has been adopted to demonstrate the novel concepts defined by the research. A cutting tool often consists of an assembly of four or more components, including a number of durable parts (namely tool shank, collets and studs) that are used for holding the tool assembly in the machine, together with the consumable parts (i.e. solid tools or inserts) which are the material removal parts of tools. The cutting tools are categorized based on various machining processes such as milling, drilling, turning, grinding, boring and tapping. These tools gradually lose their accuracy and cutting capabilities over a period (tool life), in which case they are referred to as worn or spent.

The assertion made in this case study is that the adoption of a recovery or recycling procedure for cutting tools promises to provide significant financial benefits within the majority of machining applications. This is apparent from consideration of the following:

1. A typical metalworking SME holds more than a 1000 tools at an average cost of $£ 75$ per year.
2. The cost of cutting tools is often as much as $15-20$ per cent of overall production costs.

3. The number of worn tools produced by a small computer numerical control (CNC) machining shop is typically over 500 per year.

4. Less than 50 per cent of the useable tool life is often being utilized at a CNC machining station.

5. Less than 15 per cent of refurbishable tools are being recycled.

The focus of this study is on the recovery of the consumable components of cutting tools, which are usually made of one of three materials, namely highspeed steel, tungsten carbide or ceramic. These consumable items can be classified as refurbishable (i.e. they can be recovered for a limited number of times before they are scrapped) or throwaway (which are scrapped when they are worn). The recovery of tools is often based on three major processes of regrinding, recoating and material recycling. One further issue to consider is that in some cases where a specialized material is being cut (e.g. titanium) the tools will become impregnated with the hazardous material and are unrecoverable. This requires specific disposal procedures at the end of the tool life.

The major actors for cutting tools EoL recovery are shown in Fig. 4 and consist of tool manufacturers, tool suppliers and retailers, tool users across a range of industrial sectors, tool recyclers (consisting of tool regrinding and/or recoating companies) and material recyclers (who take back unrefurbishable tools as scrap for material reclamation). In this study the following terminology for realization of cutting tools recovery has been defined:

1. Tool rework is the capability to regrind limited tools internally within the manufacturing enterprise. 


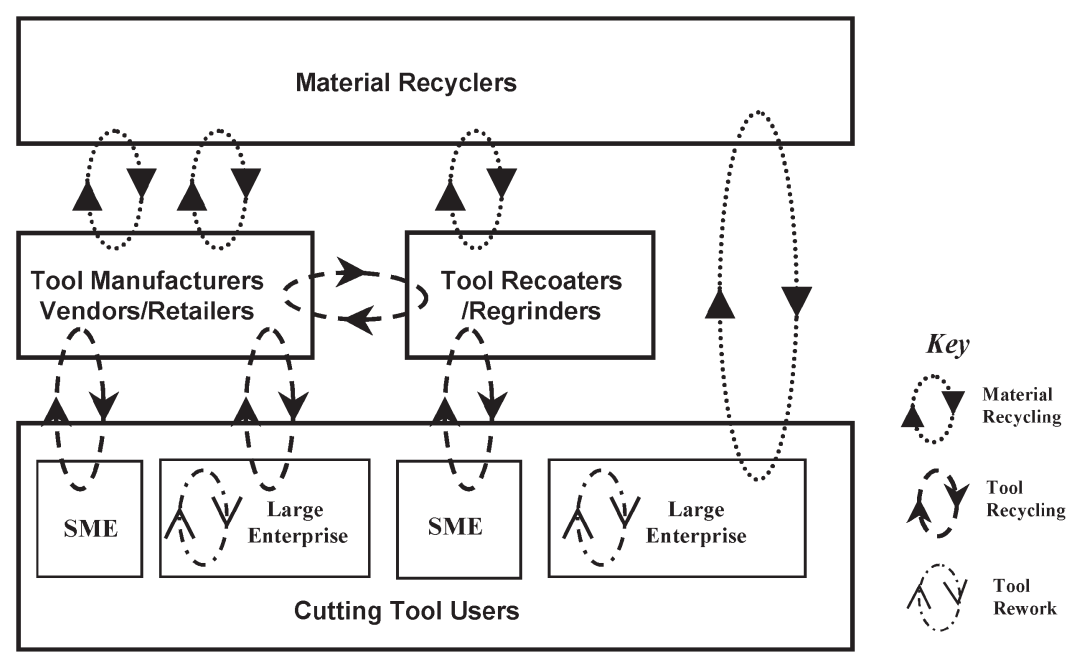

Fig. 4 A framework for recovery and recycling of cutting tools

2. Tool recycling is the ability to take back the used worn tools by external companies (i.e. the original tool supplier or a third party tool refurbishing company) for the purpose of regrinding, recoating and resupplying.

3. Material recycling is the return of worn or used tools for reclamation of material.

\subsection{Information modelling and design}

At present, the recovery of cutting tools is not supported by a formal information system, resulting in significant restrictions for adoption of the tool recovery procedures. This research proposes the development of one such system, referred to as a tool recovery information system (TRIS), which has been realized in three stages, namely:

(a) specification of tool recovery information using the Booch methodology,

(b) Implementation of a data repository using the Microsoft Access database management system, and

(c) implementation of an information network, using a three-tier Web-based architecture.

Figure 5 illustrates the typical information related to recovery of cutting tools using a Booch representation, based on the PR information categories identified in section 4.1. The tool recovery information has been grouped into three classes representing refurbishable solid cutting tools, recovery processes and used tools. The solid cutting tool class in addition to common information such as tool identification, technical specification, tool assembly description, tool supplier/manufacturer, tool presetting data and tool life also includes information related to the possible tool recovery (regrinding) options, times, costs and more detailed data on material types and characteristics for recycling purposes. The tool recovery process class contains mainly information related to various types of recovery processes (i.e. regrinding, recoating and material recycling) and recovery actors which may be the tool user (through internal tool reworking activities), the original tool manufacturer, and an independent tool recoverer or material recycler. The used tool class contains the utilization history for a particular cutting tool which includes the material cut, speed and location for tool usage, and the history of previous recovery activities and actors on this tool.

The data structures defined through the Booch representation have been utilized to design and implement a data repository system for TRIS, using the Microsoft Access database management system. This database consists of a range of tables, including those for material, recovery processes, recovery actors, solid cutting tool and used tool. The typical data stored and maintained within these tables, together with the data relationships are depicted in Fig. 6. The web-based information network for TRIS has been developed using the commonly adopted three-tier architecture as shown in Fig. 7. The first tier includes application clients, i.e. a web browser that is linked to the system by the connecting web server (in this case a Jakarta Tomcat web server). This tier allows the user to interact (to insert and collect data) with the system. The second tier is the application tier, which consists of a software module developed using the Java server pages for accomplishing the computational activities in response to user requests, according to a predefined set of business logic rules. The third tier is the persistent data storage level which stores and maintains data for the application, i.e. the Microsoft Access database. Figure 8 depicts the utilization of these screens by the major actors involved in the cutting tool recovery. This provides an effective view of a distributed information system to support a wide range of requirements by actors within a tool supply and recovery chain. 


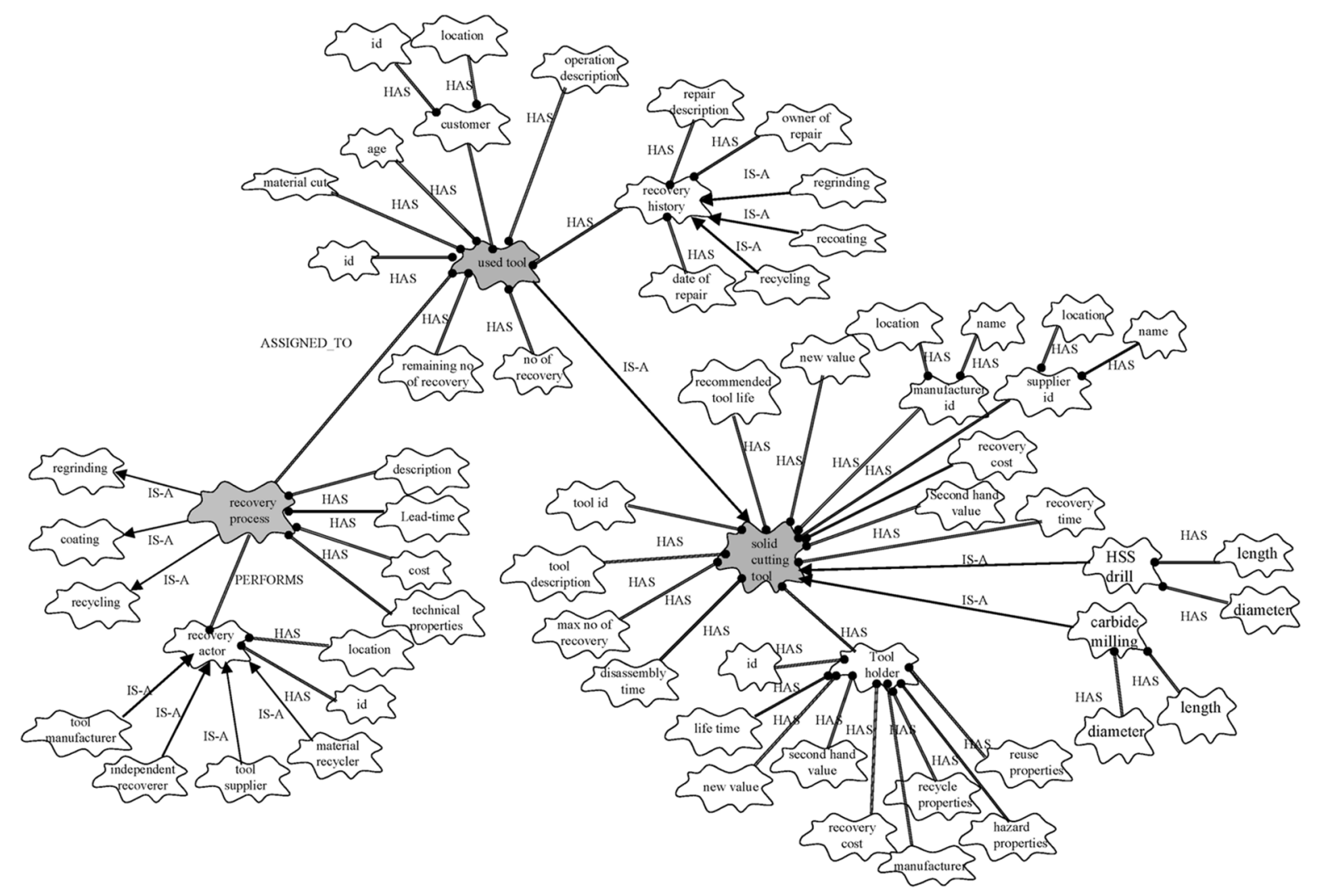

Fig. 5 Booch representation of PR information for TRIS

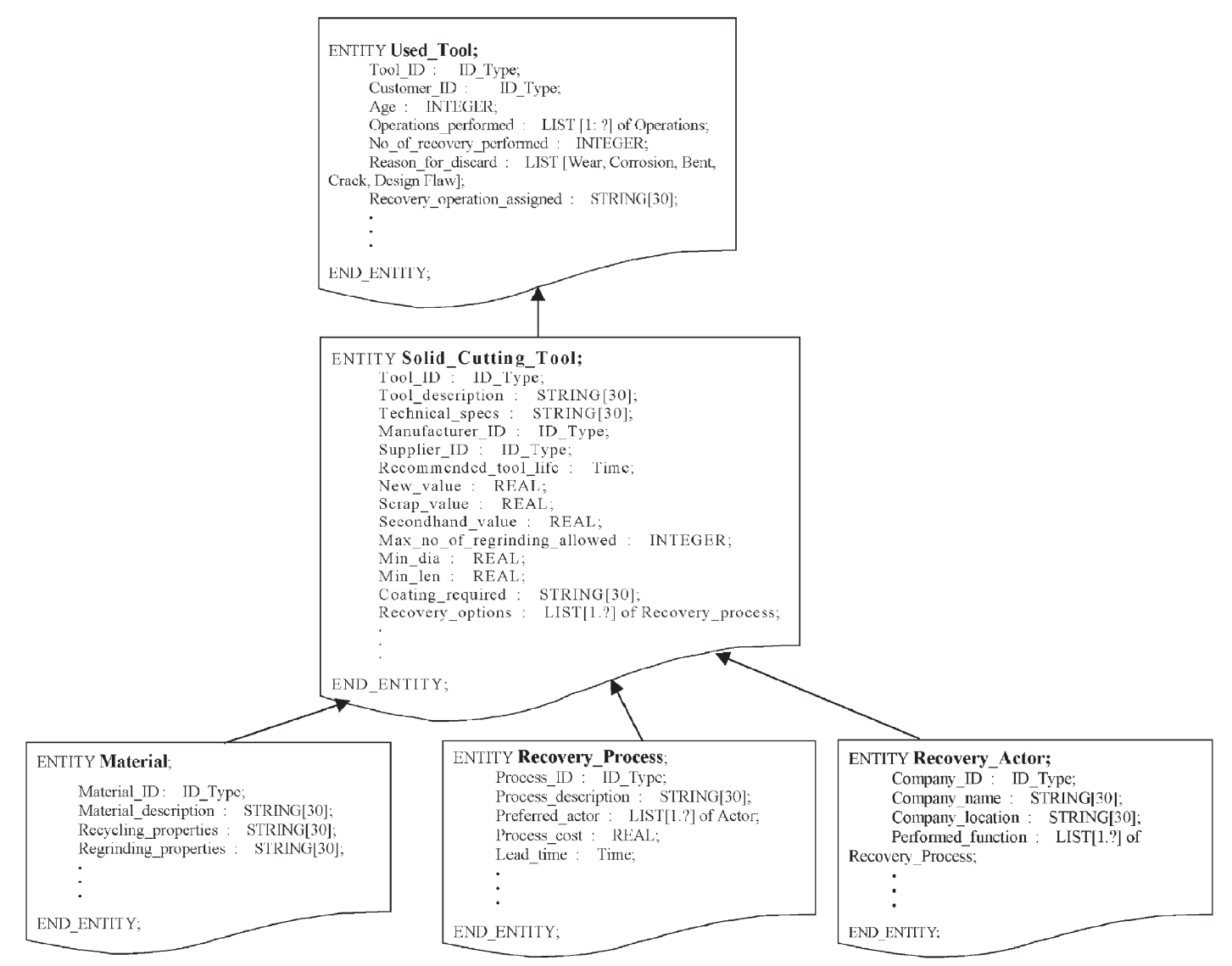

Fig. 6 Sample tables within the tool recovery data repository system 


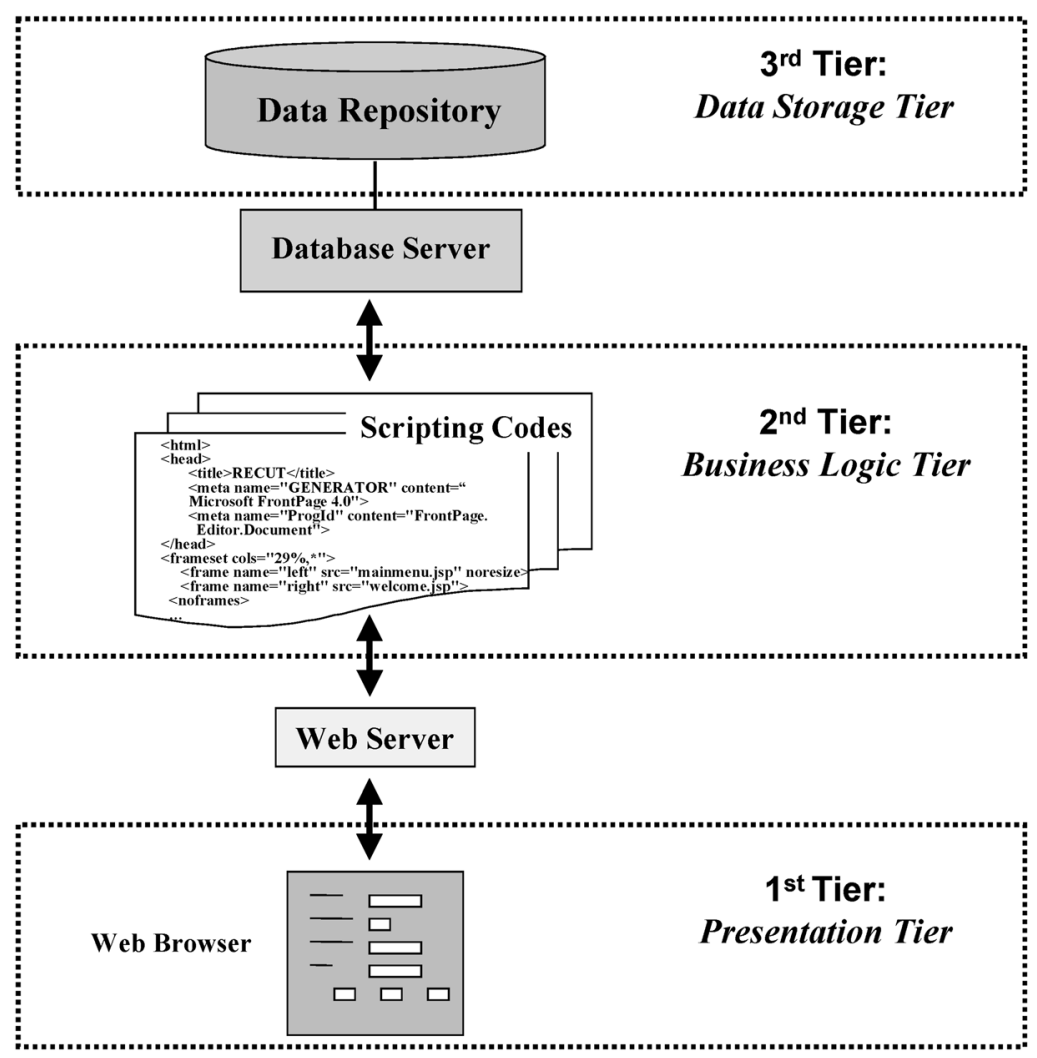

Fig. 7 Web application architecture

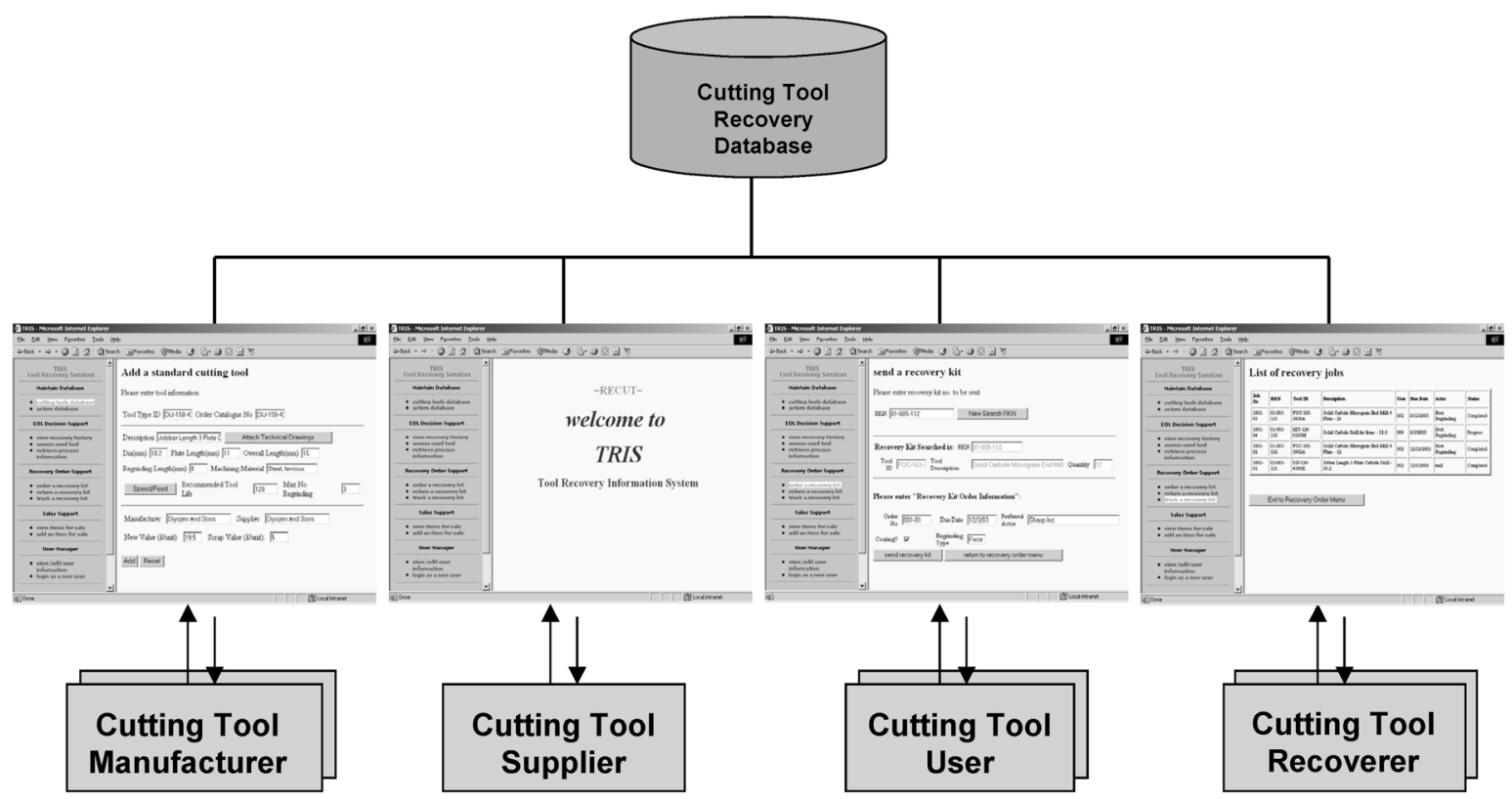

Fig. 8 The utilization of TRIS within a tool supply and recovery chain

\subsection{Functional viewpoint}

The typical users of TRIS include cutting tool manufacturer and/or supplier, a number of cutting tool users, tool regrinding companies and material recyclers. This Webbased information system provides remote access for these users over the Internet to store, share and maintain their data relating to recovery of cutting tools. Four major functional modules have been developed in TRIS based on the consultation with industrial partners of the research:

1. The databases maintenance module provides access for the (authorized) user to view, add and edit data in the 


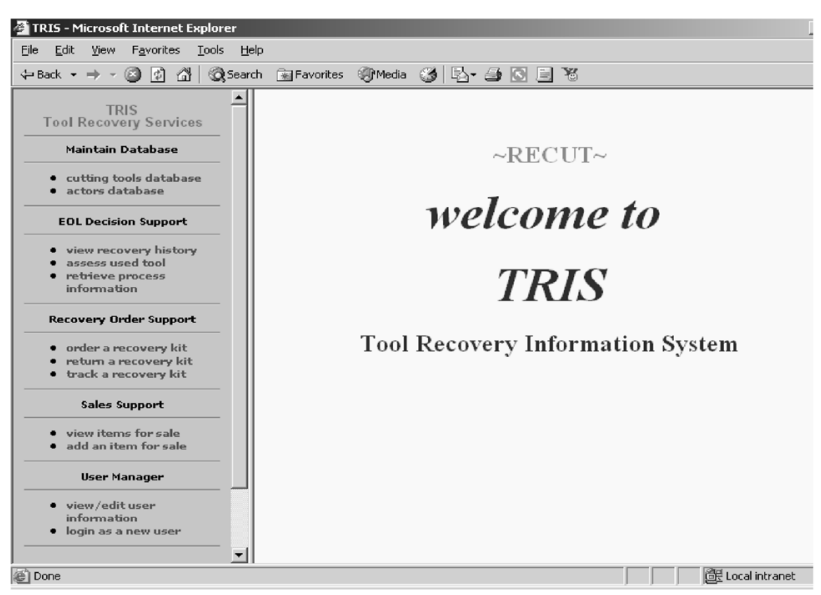

a) Home Page for TRIS

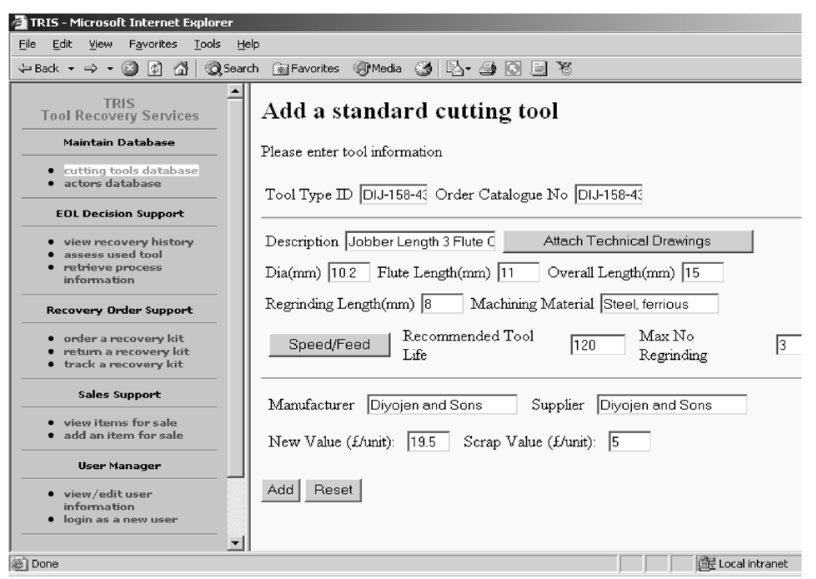

c) Add/Edit Cutting Tool Screen

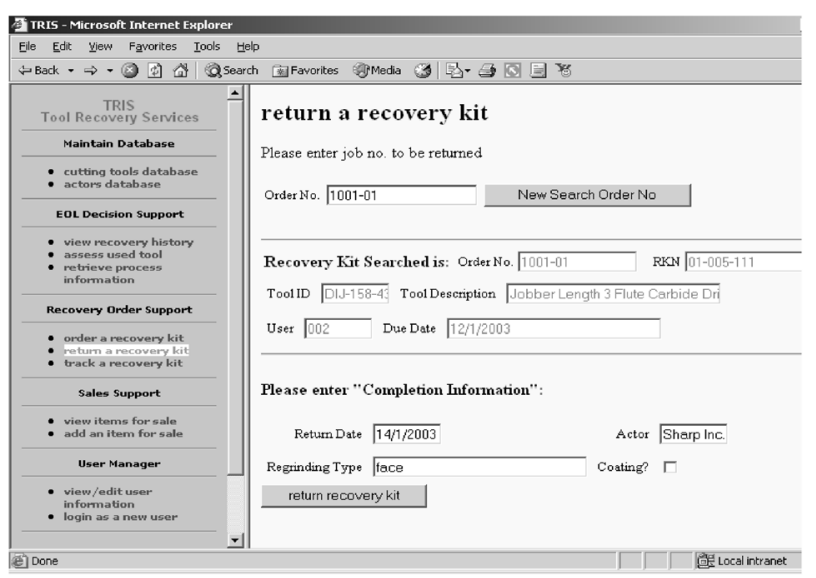

e) Monitoring the Progress of Recovery Kit

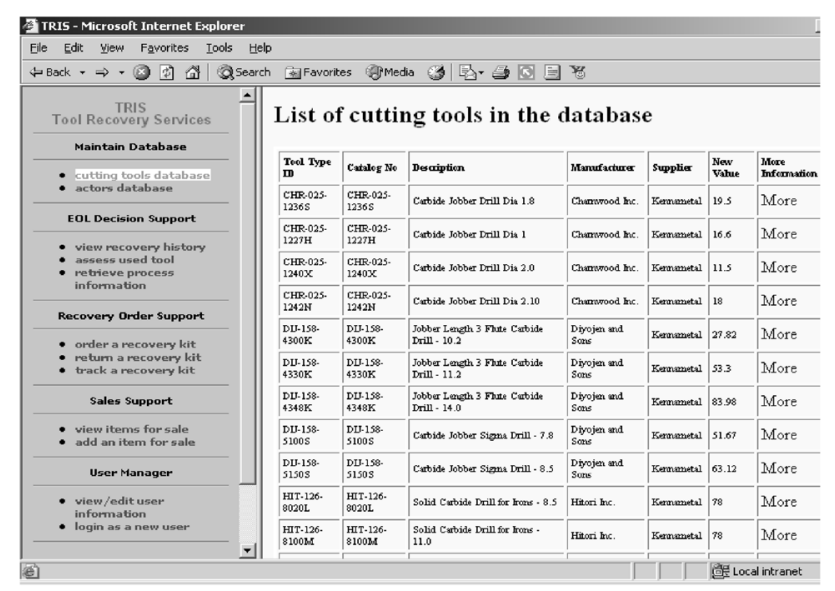

\section{b) Cutting Tool Database}

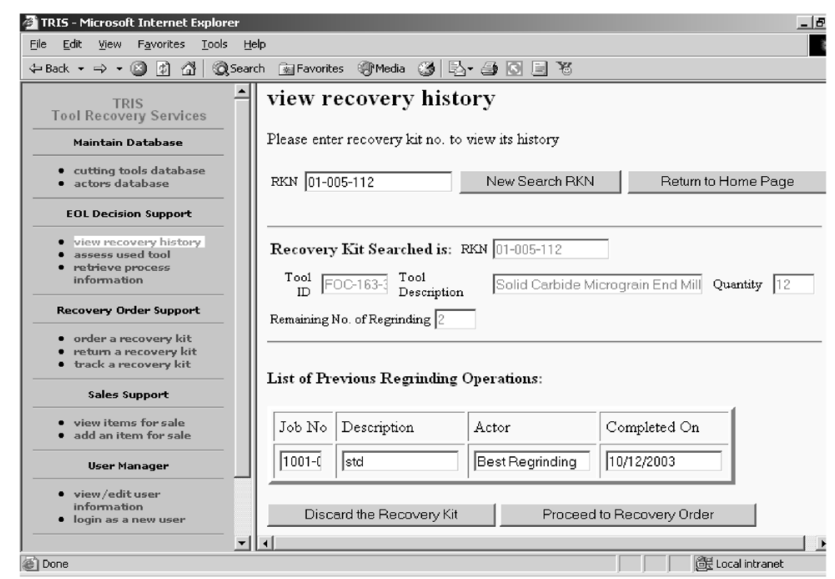

\section{d) Recovery History Screen}

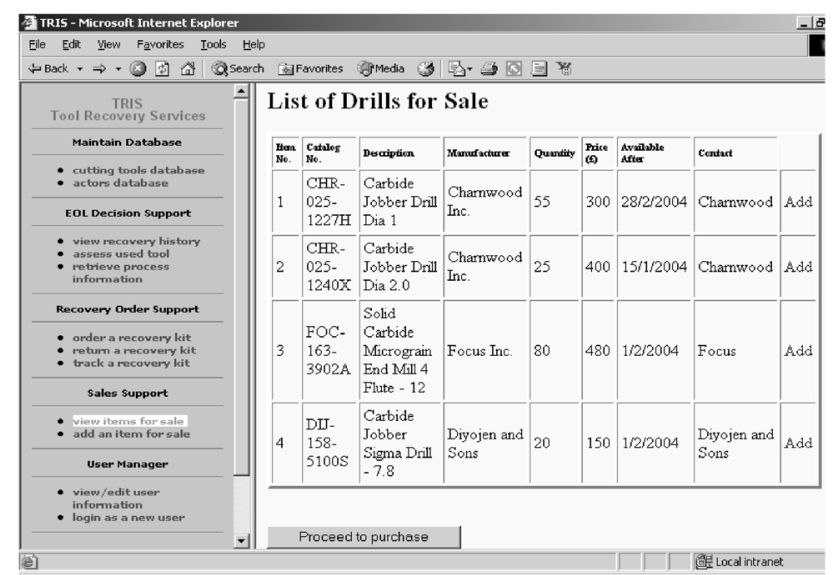

\section{f) List of Used/Reground Tools for Sale}

Fig. 9 Example screens from TRIS

related databases. Figures 9 a to c show a subset of the user interface screens for this module.

2. The EoL decision support module provides support in identifying the most suitable recovery process for a given cutting tool based on its use and regrinding history (see Fig. 9d), EoL tool condition and feasible regrinding processes.

3. The recovery order module is used by tool users, tool manufacture and tool regrinder to place a recovery order for a specific collection of tools (referred to as 
tool recovery kit), to coordinate and monitor its progress, and to provide feedback on order completion (see Fig. 9e).

4. The sales support module is used to share information related to used tools, reground tools and scrapped tools for resale to various actors within the tool supply and recovery chain and to provide an on-line sales and purchase facility, referred to as e-tool (see Fig. 9f).

\section{CONCLUDING DISCUSSION}

The ever-growing amount of national and international environmental legislation is necessitating the adoption of PR procedures in an increasing number of industrial sectors. Furthermore, modern consumer pressures for reduction in the negative impact on the environment is another indicator of the inevitability of the inclusion of PR procedures within the majority of manufacturing applications in the near future. At present, the wider adoption of PR activities are hindered due to a number of factors, such as the following:

1. The recovery of products is not economically viable in many industrial sectors.

2. There is a lack of independent recoverers in many applications or, where they exist, the required recovery capacity is inadequate.

3. There is general resistance by manufacturing companies to share information on their materials, product design and product utilization due to modern pursers in a highly competitive global market.

4. The varying marketing implications for adoption of PR may be very positive in applications such as recycling of plastic bottles and carrier bags, whereas the use of recycled or reconditioned parts within the automotive industry may not necessarily encourage an increase in sales.

5. In general the PR activities are not supported with appropriate information technology (IT) software tools.

It is recognized that, as a result of these issues, adoption of PR procedures are not encouraged to a wider scale within manufacturing companies and, in particular, SMEs. The authors argue that desired levels of reduction in negative impacts on the environment can only be achieved through development of a simple, economical and systematic approach for the adoption of PR within SMEs. In this context, to achieve such a large-scale adoption of PR, the following assertions are made by the research reported in this paper:

1. The scope of the traditional product supply chain must be extended to include the PR activities and actors, through development of novel concepts for an integrated 'product supply and recovery chain'.

2. A systematic methodology encompassing the considerations for a wide range of issues including those related to business, technological, operational planning and information management requirements for implementation of PR activities must be adopted.

3. Bespoke information systems and IT software tools must be designed and developed to underpin the implementation of PR activities.

The PRIME methodology presented in this paper provides one such systematic approach to support the mass inclusion of PR within various manufacturing applications, based on an integrated view for a product supply and recovery chain. Furthermore, the Webbased information systems presented provide an efficient tool to support the information requirements and to enable the close integration of various PR activities. The future of this research is based on the use of such distributed information systems as facilitator for the increase in 'service provision' as opposed to the traditional view of 'product ownership'.

\section{REFERENCES}

1 Guide, V. D. R., Jayaraman, V., Srivastava, R. and Benton, W. C. Supply-chain management for recoverable manufacturing systems. Interfaces, 2000, 30(3), 125-142.

2 Gungor, A. and Gupta, S. M. Issues in environmentally conscious manufacturing and product recovery: a survey. Computers Ind. Engng, 1999, 36(4), 811-853.

3 Alting, L. and Legarth, J. B. Life cycle engineering and design. Ann. CIRP, 1995, 44(2), 569-580.

4 Harjula, T., Rapoza, B., Knight, W. A. and Boothroyd, G. Design for disassembly and the environment. Ann. CIRP, 1996, 45(1), 109-114.

5 Navin-Chandra, D. The recovery problem in product design. J. Engng Des., 1994, 5(1), 65-86.

6 Lambert, A. J. D. Optimal disassembly of complex products. Int. J. Prod. Res., 1997, 35(9), 2509-2523.

7 Das, S. K., Yedlarajiah, P. and Narendra, R. An approach for estimating the end-of-life product disassembly effort and cost. Int. J. Prod. Res., 2000, 38(3), 657-673.

8 Seo, K. K., Park, J. H. and Jang, D. S. Optimal disassembly sequence using genetic algorithms considering economic and environmental aspects. Int. J. Advd Mfg Technol., 2001, 18, 371-380.

9 Hu, D., Hu, Y. and Li, C. Mechanical product disassembly sequence and path planning based on knowledge and geometry reasoning. Int. J. Advd Mfg Technol., 2002, 19, 688-696.

10 Krikke, H. R., van Harten, A. and Schuur, P. C. On a medium term product recovery and disposal strategy for durable assembly products. Int. J. Prod. Res., 1998, 36(1), 111-139.

11 Goggin, K. and Browne, J. The resource recovery level decision for end-of-life products. Prod. Planning Control, 2000, 11(7), 628-640.

12 Lee, S. G., Lye, S. W. and Khoo, M. K. A multi-objective methodology for evaluating product end-of-life options and disassembly. Int. J. Advd Mfg Technol., 2001, 18, 148-156. 
13 Erdos, G., Kis, T. and Xirouchakis, P. Modelling and evaluating product end-of-life options. Int. J. Prod. Res., 2001, 39(6), 1203-1220.

14 Bufardi, A., Sakara, D., Gheorghe, R., Kritsis, D. and Xirouchakis, P. Multiple criteria decision aid for selecting the best product end of life scenario. Int. J. Computer Integrated $M f g, 2003, \mathbf{1 6}(7-8)$, 526-534.

15 Guide, V. D. R., Kraus, M. E. and Srivastava, R. Scheduling policies for remanufacturing. Int. J. Prod. Economics, 1997, 48(2), 187-204.

16 Kizilkaya, E. and Gupta, S. M. Material flow control and scheduling in a disassembly environment. Computers Ind. Engng, 1998, 35(1-2), 93-96.

17 Van der Laan, E., Salomon, M. and Dekker, R. An investigation of lead-time effects in manufacturing/remanufacturing systems under simple PUSH and PULL control strategies. Eur. J. Opl Res., 1999, 115(1), 195-214.

18 Kim, H. J., Lee, D. H., Xirouchakis, P. and Zust, R. Disassembly scheduling with multiple product types. CIRP Ann.-Mfg Technol., 2003, 52(1), 403-406.

19 Guide, V. D. R., Jayaraman, V. and Srivastava, R. Production planning and control for remanufacturing: a state-ofart survey. Robotics Computer Integrated Mfg, 1999, 15(3), 221-230.

20 Richter, K. and Sombrutzki, M. Remanufacturing planning for the reverse Wagner/Whitin models. Eur. J. Opl Res., 2000, 121(2), 304-315.

21 Klausner, M. and Hendrickson, C. T. Reverse-logistics strategy for product take-back. Interfaces, 2000, 30(3), 156-165.

22 Fleischmann, M., Boemhof-Ruwaard, J. M., Dekker, R., van der Laan, E., van Nunen, J. A. E. E. and van Vasenhove, L.N. Quantitive models for reverse logistics: a review. Eur. J. Opl Res., 1997, 103, 1-17.
23 Fleischmann, M., Krikke, H. R., Dekker, R. and Flapper, S. D. P. A characterisation of logistics networks for product recovery. Omega, 2000, 28, 653-666.

24 Goggin, K., Reay, E. and Browne, J. Modelling end-of-life product recovery chains - a case study. Prod. Planning Control, 2000, 11(2), 187-196.

25 Guide, V. D. R. and Jayaraman, V. Product acquisition management: current industry practice and a proposed framework. Int. J. Prod. Res., 2000, 38(16), 3779-3800.

26 Spath, D., Hartel, M. and Tritsch, C. Recycling-oriented information management: a prerequisite for life cycle engineering. J. Engng Des., 1996, 7(3), 251-264.

27 Lambert, A. J. D., Jansen, M. H. and Splinter, M. A. M. Environmental information systems based on enterprise resource planning. Integrated Mfg Systems, 2000, 11(2), 105-112.

28 Ferguson, N. and Browne, J. Issues in end-of-life product recovery and reverse logistics. Prod. Planning Control, 2001, 12(5), 534-547.

29 Rahimifard, A., Newman, S. T. and Rahimifard, S. A methodology to support the implementation of product recovery. In Proceedings of the 1st International Conference on 